\title{
The Role of Family Education in Facing Millenial Era Through Moral Development in Children
}

\author{
Laely Rizki Amalia, Anggi Setiyaningsih, Haani Aulia Sabina, Joharman, Siti \\ Fatimah
}

Universitas Sebelas Maret

elyamalia15@gmail.com

\section{Article History}

accepted 24/09/2019

approved 01/10/2019

published 01/12/2019

\begin{abstract}
Education is a conscious and planned effort to realize the atmosphere and learning process of students so that they can actively develop their potential to have spiritual, religious, self-control, intelligence, noble character, and skills needed by themselves and the community. Given in this millennial era, technology is increasingly sophisticated and advanced. The threat that may not be realized by the current generation is the moral degradation of the nation. The role of the family in educating children in the millennial era takes a very important role in overcoming this, so children need intensive supervision from parents. The family as a foundation for character and character for children. Education and character formation of children can't be separated from parenting parents. Where the relationship between parents and children can be established properly, so that automatically an agreement occurs in every decision making. The education bureaucracy must be able to focus on strategic policies and be able to create and be able to bridge between the pure values of the nation and existing developments.
\end{abstract}

Keywords: Education, parents, children, millennial era, moral

\begin{abstract}
Abstrak
Pendidikan merupakan suatu usaha sadar dan terencana untuk mewujudkan suasana dan proses pembelajaran peserta didik agar secara aktif dapat mengembangkan potensi dirinya untuk memiliki kemampuan spiritual, keagamaan, pengendalian diri, kecerdasan, akhlak mulia, serta keterampilan yang diperlukan dirinya dan masyarakat. Dalam Era millenial ini teknologi semakin canggih dan maju. Ancaman yang mungkin kurang disadari oleh generasi saat ini yaitu degradasi moral bangsa. Peran keluarga dalam mendidik anak di era millenial mengambil peran yang sangat penting dalam mengatasi hal ini, sehingga anak perlu pengawasan yang intensif dari orang tua. Keluarga sebagai pondasi akhlak dan karakter bagi anak-anak. Pendidikan dan pembentukan karakter anak tidak lepas dari pola asuh orang tua. hubungan antara orang tua dengan anak dapat terjalin dengan baik, sehingga secara otomatis terjadi kesepakatan dalam setiap pengambilan keputusan. Birokrasi pendidikan harus mampu fokus pada kebijakan yang strategis serta mampu mengkreasikan serta mampu menjembatani antara nilai-nilai murni bangsa dan perkembangan yang ada.
\end{abstract}

Kata kunci : Pendidikan, orang tua, anak, era millenial, moral

Social, Humanities, and Education Studies (SHEs): Conference Series https://jurnal.uns.ac.id/shes

p-ISSN 2620-9284

e-ISSN 2620-9292 


\section{PENDAHULUAN}

Dalam era milenial ini, dimana para generasi yang lahir di era kemajuan teknologi dan informasi. Mereka menikmati berbagai kemudahan akses informasi, transportasi dan berbagai fasilitas modern lainnya yang tersedia saat ini seiring kemajuan zaman termasuk teknologi dalam dunia pendidikan. Pendidikan karakter sangat dibutuhkan bagi anak tidak hanya pengetahuan dan keterampilan saja. Djudjun Djaenuddin Supriadi dalam artikelnya yang berjudul "Program Pendidikan Karakter di Lingkungan BPK PENABUR JAKARTA", dalam tulisannya, Ketut Sumarta mengungkapkan bahwa Pendidikan nasional kita cenderung hanya menonjolkan pembentukan kecerdasan berpikir dan menepikan penempatan kecerdasan rasa, kecerdasan budi, bahkan kecerdasan batin. Dari sini lahirlah manusia yang berprestasi, tetapi tiada kecerdasan budi sekaligus sangat berketergantungan. Banyak dari mereka yang masih memiliki karakter yang tidak baik atau kurang terpuji. Dalam hal ini terjadi kemerosotan moral yang mana harus segera di tangani melalui Pendidikan keluarga dengan penanaman moral yang baik pada anak. Peran pendidikan dalam membangun moral bangsa Indonesia sejak zaman perjuangan, kemerdekaan hingga zaman millennial sekarang ini sangatlah besar. Keluarga merupakan lingkungan pertama bagi anak untuk mendapatkan Pendidikan dalam membentuk pribadi yang bermoral. Pendidikan merupakan sejumlah pengalaman dari seseorang atau kelompok untuk memahami sesuatu yang sebelumnya belum mereka pahami. Pengalaman itu terjadi karena adanya interaksi antara seseorang atau kelompok dengan lingkungannya. Interaksi itu menimbulkan proses perubahan (belajar) pada manusia dan selanjutnya proses perubahan itu menghasilkan perkembangan (development) bagi kehidupan seseorang atau kelompok dalam lingkungannya. Pendidikan juga menyediakan karakter dasar dari kebutuhan manusia untuk menjadi pribadi yang dewasa dan bertanggung jawab. Dalam arti ini, pengetahuan dilihat oleh John Locke sebagai sarana untuk membentuk manusia menjadi pribadi yang bermoral. Seluruh tingkah laku diarahkan pada usaha untuk membentuk pribadi manusia yang baik sesuai dengan karakter dasar sendiri sejak diciptakan (Beni S. Ambarjaya, 2012:7-8).

Seiring berjalannya waktu, generasi muda saat ini justru lebih mudah terpengaruh oleh arus globalisasi yang berdampak negatif bagi mereka, sebagai contoh kecanduan gadget. Seperti yang dilansir dari detiknews.com Komisioner KPAI Bidang Pendidikan, Retno Listyarti, kepada wartawan, Kamis (12/9/2019) mengatakan bahwa kecanduan gadget, termasuk ponsel, dapat berdampak pada kesehatan fisik dan psikis (mental) anak, di antaranya anak dapat menimbulkan masalah kesehatan mental dan perubahan perilaku, hingga depresi. Mereka mungkin juga menjadi agresif dan mudah tersinggung jika orang tua tidak memberi mereka akses menggunakan ponsel atau tablet. Kasus anak mengancam guru dengan celurit lantaran ponsel disita adalah bentuk si anak agresif dan tidak bisa mengelola emosi dengan baik. Mental murid bisa terganggu gara-gara gadget. Itu menjelaskan kenapa murid di Gunungkidul sampai berani mempersenjatai dirinya dengan sabit demi mendapatkan ponselnya kembali, barang yang sudah menjadi candu bagi sang anak. Anak menjadi tak bisa menahan diri dan tidak bisa mengendalikan emosi sehingga tidak memikirkan dampak dari perbuatan yang dilakukannya. Hal Ini berbahaya bagi perkembangan masa depan anak di masa dewasa. Anak juga bisa mengalami kecemasan, kesepian, rasa bersalah, hingga depresi apabila terpapar ponsel secara berlebihan.

Berdasarkan hal tersebut, dibutuhkan suatu cara untuk mengatasi permasalahan tersebut dari lingkup terkecil seperti keluarga. Keluarga merupakan Pendidikan pertama yang menyediakan kebutuhan biologis bagi anak dan sekaligus memberikan penanaman karakter yang baik pada anak, sehingga menghasilkan pribadi yang bermoral. Peran keluarga di dalam pembinaan moral di era millenial ini tentunya sangat penting. Masing-masing anggota keluarga mempunyai tanggung jawab untuk saling memberikan perhatian kepada anggota keluarga lainnya. Mengingat bahwa 
sebuah keluarga adalah pendidikan pertama bagi anak, maka Pendidikan keluarga perlu mendapatkan perhatian dan penelaahan. Oleh karenanya, peneliti merumuskan masalah yang akan dikaji dalam artikel ini adalah "Bagaimana Pengaruh Pendidikan Keluarga dalam Menghadapi Era Millenial melalui Penanaman Moral pada Anak." Hasil penelitian ini diharapkan dapat menjadi pertimbangan dalam usaha peningkatan peran keluarga dalam mendidik anak ke arah pembinaan moral yang lebih baik.

\section{METODE}

Penelitian ini menggunakan metode penelitian deskriptif kualitatif. Subjek penelitian yang digunakan peneliti adalah orang tua dengan profesi yang berbeda . Kriteria subjek orang tua adalah memiliki anak milenial, berdomisili di Kebumen, dan bersedia untuk menjadi narasumber secara sukarela. Teknik pengumpulan data pada penelitian ini menggunakan teknik wawancara. Wawancara dalam penelitian ini bertujuan memperoleh informasi secara mendalam dan mengeksplorasi secara fleksibel tentang peran pendikan keluarga kepada anak generasi millenial dalam mempersiapkan menghadapi tantangan-tantangan revolusi industri 4.0.

Penelitian ini menggunakan analisis data yang telah dikembangkan oleh Miles dan Huberman (Emzir,2010) dengan menggunakan analisis model interaktif dengan tiga prosedur yaitu reduksi data, penyampaian data dan menarik kesimpulan. Reduksi data dalam penelitian ini dilakukan dengan memilah dan memilih, mengelompokkan, megarahkan serta data pokok yang penting dan tidak penting dari sumber data wawancara yang telah dilakukan kemudian dilakukan penyajian data. Penyajian data dari penelitian kami bertujuan untuk memberikan kemungkinan penarikan kesimpulan. Tahapan terakhir analisis data dengan menarik kesimpulan dari kategori-kategori data yang telah direduksi dan disajikan untuk selanjutnya menuju kesimpulan akhir yang mampu menjawab permasalahan.

\section{HASIL DAN PEMBAHASAN}

Wawancara mengenai pendidikan keluarga yang telah dilakukan untuk mendeskripsikan kondisi sebenarnya mengenai bagaimana peran pendidikan keluarga terhadap penggunaan gadget dan teknologi pada anak, didapatkan hasil bahwa sebagian besar orang tua memang sudah memberikan gadget kepada anak sejak usia dini. Dengan rata-rata usia 3 - 15 tahun, anak sudah terpapar dengan pengaruh gadget dan tayangan televisi. Padahal perlu diketahui bahwa periode perkembangan anak sangat sensitif pada usia tersebut, dimana pada periode ini sering disebut dengan the golden age. Seluruh aspek perkembangan kecerdasan seperti kecerdasan intelektual, emosi, dan spiritual mengalami perkembangan yang luar biasa sehingga mempengaruhi dan menentukan perkembangan selanjutnya yaitu pembentukan karakter, kepribadian, dan kemampuan kognitif anak.

Berdasarkan wawancara dengan subjek orang tua yang berbeda profesi, diperoleh beberapa gambaran peran keluarga dalam mendidik dan mengawasi penggunaan gadget dan ketika anak menonton televisi.

Peran orang tua yang berprofesi sebagai guru, menunjukkan bahwa mereka sudah memberikan gadget dan membolehkan anak menonton televisi sejak usia dini. Orang tua tetap memberikan pengawasan dan pendampingan bagi anak. Anak hanya diperbolehkan memakai gadget dan menonton televisi pada sore hari saat orang tua sudah berada dirumah. Ketika anak mengoperasikan gadget, orang tua hanya membolehkan anak menonton video atau game offline tanpa akses internet, sehingga anak lebih terkontrol. Dampak pada anak ketika mereka dibatasi dalam menggunakan gadget adalah anak menjadi lebih disiplin dan tidak memaksa ketika waktu yang sudah diberikan habis. Cara orang tua yang berprofesi guru mendidik anak adalah dengan cara bergantian peran, selain itu mereka selalu mencontohkan hal yang baik ketika 
sedang berkumpul misalnya selalu berdoa, mencuci piring bersama supaya anak bertanggung jawab, dan menerapkan kejujuran.

Peran orang tua yang berprofesi sebagai karyawan, menunjukkan hasil bahwa mereka juga memberikan anak gadget dan membolehkan anak menonton televisi sejak usia dini. Perbedaannya adalah para orang tua yang berprofesi sebagai karyawan hanya meminjami anak gadget dengan rata-rata waktu 1-2 jam dengan pengawasan langsung dari orang tua.

Peran orang tua yang berprofesi sebagai pedagang, menunjukkan hasil bahwa mereka memberikan gadget kepada anak hanya setelah mereka pulang dari sekolah selebihnya gadget diambil kembali. Pada malam harinya anak diberi waktu untuk belajar dan tidak lagi dipinjamkan gadget. Orang tua yang berprofesi sebagai pedagang menanamkan sikap kejujuran pada anak. Mereka memberikan kebebasan ketika anak memainkan gadget dengan syarat apabila anak menggunakan gadget untuk hal yang buruk maka orang tua akan menyita gadget tersebut.

Peran orang tua yang berprofesi ibu rumah tangga dalam mendampingi anak bermain gadget yaitu mereka tidak memantau langsung bagaimana anak mengoperasikan gadget. Hal ini karena kesibukan ibu dalam menyelesaikan pekerjaan rumah. Sehingga anak diberi kebebasan dan menjadi tidak terkontrol. Akan tetapi orang tua tetap mengingatkan dan mengatur waktu belajar untuk anak.

Berdasarkan data hasil penelitian, dapat ditarik kesimpulan rata-rata orang tua memberikan kebebasan kepada anak mereka untuk memakai gadget, akan tetapi mereka tetap memberikan batasan waktu. Pengaksesan gadget pada anak sebagian besar untuk memainkan game, menonton film kartun, mencari materi pelajaran, dan sebagai alat komunikasi dengan sekolah atau orang tua. Faktor-faktor yang mendukung sebagian besar orang tua memberikan gadget kepada anak didasari adanya pengetahuan mengenai dampak positif penggunaan gadget pada anak seperti memberikan pembelajaran dengan perkembangan teknologi modern bagi anak sehingga dapat menambah ilmu pengetahuan anak tentang dunia luar, dan dapat merangsang perkembangan otak anak. Ada pula orangtua yang menganggap bahwa dengan memberikan gadget maka akan membuat anak menjadi pintar dan agar anak tidak bermain keluar rumah.

Hasil riset dipaparkan dari lembaga riset terkemuka, menunjukan bahwa keluarga di masa kini telah menggunakan perangkat media berupa gadget (smartphone). Lembaga survey The Halifax Insurance Digital Home menemukan sepertiga 7-8 tahun (31\%), dua pertiga dari anak usia 9-11 tahun (63\%), dan hampir sembilan dari sepuluh tahun usia 12-14 (88\%) sekarang memiliki gagdet. Namun, $60 \%$ dari orang tua merasa bahwa jumlah waktu anak-anak menghabiskan menggunakan teknologi berdampak pada waktu yang dihabiskan dengan keluarga dan teman-teman.

Konsekuensi mengenalkan gadget sejak dini pada anak memang sangat tergantung pada kesiapan orangtua dalam mengawasi anak saat bermain gadget. Semua orang tua perlu memahami peran penting mereka dalam pemanfaatan gadget pada anak. Orang tua perlu menerapkan sejumlah aturan kepada anak-anaknya dalam menggunakan gadget. Orang tua bisa memahami dan menjelaskan mengenai konten yang ada pada gadget sehingga gadget dapat dimanfaatkan secara efektif oleh anak. Apabila tidak ada pendampingan orang tua saat penggunaan gadget pada anak maka anak akan menerima segala hal yang diperoleh dari bermain gadget tersebut. Hal ini bisa membuat anak berperilaku tidak sesuai atau menyimpang dengan norma dan aturan yang ada.

Perubahan mempunyai dampak yang besar terhadap kualitas hubungan antara anak usia sekolah dan orangtua mereka (Seifert \& Hoffnung 1994). Peran ayah dan ibu dalam mendampingi penggunaan gadget pada anak mempunya peran pendukung yaitu adanya pengetahuan mengenai manfaat maupun resiko penggunaan gadget pada 
anak, sehingga menumbuhkan kesadaran yang lebih tinggi akan pentingnya mendampingi anak pada saat bermain gadget. Dalam hal ini peran ayah juga memiliki kekurangan yang menjadi faktor penghambat seperti keterbatasan waktu ayah untuk bersama anak karena kondisi pekerjaan yang menyibukkan. Adapun peran ibu yang menjadi faktor penghambat yaitu aktivitas ibu dalam melakukan pekerjaan rumah.

Sebaiknya ada kerja sama antara ayah dan ibu dalam melakukan pendidikan keluarga kepada anak dengan penamaman moral sehingga dapat mengurangi dampak negatif penggunaan gadget pada anak. Usaha usahanya berupa membatasi durasi anak dalam bermain gadget yaitu maksimal 15 hingga 30 menit, melakukan pengawasan dan memastikan bahwa anak-anak menggunakan gadget untuk mengakses informasi-informasi positif sebagai bahan pelajarannya, memberikan pengetahuan dan pemahaman tentang hal-hal apa saja yang boleh diakses serta halhal atau situs-situs yang tidak boleh diakses.

Berdasarkan hasil analisis chi-square yang dilansir dari E-Journal Keperawatan (e-Kp) volume 6 nomor 2, Agustus 2018, hubungan antara peran keluarga dalam menghindari dampak negatif penggunaan gadget dengan perilaku anak diperoleh nilai signifikan ( $p$-value) sebesar 0,000 $(<0,05)$ dan kesimpulan yang diperoleh adalah $\mathrm{H} 0$ ditolak. Interpretasi dari analisa ini adalah ada hubungan antara peran keluarga dalam menghindari dampak negatif penggunaan gadget pada anak dengan perilaku anak dalam penggunaan gadget di Desa Kiawa 2 Barat Kecamatan Kawangkoan Utara, dimana hubungan tersebut terdapat korelasi negatif yang signifikan, hal itu dapat dilihat bahwa semakin baik peran keluarga maka semakin baik pula perilaku anak dalam penggunaan gadget.

\section{SIMPULAN}

Keluarga merupakan Pendidikan pertama dan utama bagi perkembangan anak. Orang tua di dalam keluarga memiliki tanggung jawab penuh atas perkembangan potensi anak. Melalui Pendidikan, orang tua turut berperan dalam pembentukan moral dan karakter pada anak. Mengingat di era millenial ini teknologi semakin canggih, maka menjadi tugas tambahan bagi orang tua dalam mengontrol anak agar tidak terjadi candu terhadap teknologi. Dalam mendidik anak orang tua dapat memberikan suatu sentuhan diantaranya dengan keteladanan, kasih sayang dan perhatian.

Oleh karena itu pendidikan keluarga sangat penting diterapkan dalam keluarga di era yang serba digital. Pendidikan yang diterapkan dalam keluarga diantaranya dengan memberi contoh yang positif kepada anak dan praktik secara langsung. Seperti yang sudah diterapkan oleh beberapa orang tua yaitu dengan melatih anak melakukan pekerjaan rumah bersama-sama, selalu berdoa bersama-sama sebelum makan, memberikan batasan waktu anak antara menggunakan gadget dan menonton televisi.

Dari kesimpulan diatas dapat diperoleh beberapa saran, diantaranya dalam lingkungan keluarga orang tua harus berperan besar dalam melakukan pendidikan dan penanaman moral kepada anaknya. Orang tua sebaiknya juga meningkatkan intensitas perannya dalam mengurangi fasilitas yang menunjang terjadinya pergeseran nilai, antara lain membatasi memainkan gadget dan penayangan televisi.

Yang terpenting orang tua memperhatikan pendidikan anak mulai dari masa kanak-kanak, karena masa kanak-kanak adalah masa pembentukan kepribadian. Pada saat itu, orang tua dapat berperan lebih banyak daripada lingkungan, sehingga kesempatan ini dimanfaatkan oleh para orang tua terhadap anaknya, agar anak mampu mempunyai perisai menghadapi arus globalisasi yang menantangnya. 
DAFTAR PUSTAKA

Ambarjaya, Beni S. (2012). Psikologi Pendidikan \& Pengajaran. Yogyakarta: CAPS.

Anwar, S. (2018). Pendidikan Islam dalam Membangun Karakter Bangsa di Era Millenial. Universitas Islam Negeri Raden Intan Lampung. Jurnal Pendidikan Islam, Volume 9, No. 2, 2018. Di akses dari : http://ejournal.radenintan.ac.id/index.php/tadzkiyyah/article/viewFile/3628/2401

Damarjati, Danu. (2019). Ada Murid Ancam Guru dengan Sabit, KPAl: Gadget Bikin Anak Agresif. Di akses dari : https://m.detik.com/news/berita/d-4703333/adamurid-ancam-guru-dengan-sabit-kpai-gadget-bikin-anak-agresif

Djudjun Djaenuddin Supriadi, (2008). "Program Pendidikan Karakter di Lingkungan BPK PENABUR Jakarta," dalam Jurnal Pendidikan Penabur, nomor 10, Tahun ke 7, Juni 2008, hlm. 35

Fatimah, Siti. (2019). Perkembangan Anak Pada Masa Golden Age. Surakarta: UNS Press.

Handitya, B. (2018). Peran Pendidikan dalam Membangun Moral Bangsa di Era Disrupsi. Seminar Nasional PKn UNNES. Di akses dari: http://proceedings.id/index.php/pkn/article/view/724

Palar, Jordan dkk. (2018). Hubungan Peran Keluarga Dalam Menghindari Dampak Negatif Penggunaan Gadget Pada Anak Dengan Perilaku Anak Dalam Penggunaan Gadget Di Desa Kiawa 2 Barat Kecamatan Kawangkoan Utara. EJournal Keperawatan (e-Kp) volume 6 nomor 2, Agustus 2018. Di unduh dari https://www.google.com/url?sa=t\&rct=i\&q=\&esrc=s\&source=web\&cd=4\&ved=2 ahUKEwiE2pyV1ffkAhVX63MBHRI6BzMQFjADegQIAxAC\&url=https\%3A\%2F\% 2Fejournal.unsrat.ac.id\%2Findex.php\%2Fikp\%2Farticle\%2Fdownload\%2F2064 6\%2F20261\&usg=AOvVaw27J7sj1YQQx59WmYAQxFjC pada tanggal 30 September 2019

Pertana, Pradito. R. (2019). Murid Ancam Guru Pakai Sabit di Gunungkidul Tak dikeluarkan. Di akses dari :

https://news.detik.com/berita-jawa-tengah/d-4702511/murid-ancam-guru-pakaisabit-di-gunungkidul-tak-dikeluarkan

Seifert, K.L dan Hoffnung, R.J. (1994). Child and Adolescent Development. Boston: Houghton Mifflin compaby.

Wijaya, Novan. (2013). Membumikan Pendidikan Karakter di SD. Yogyakarta: ARRUZZ MEDIA.

Yudatama, Satria dkk. Smartphone Dan Keluarga (Deteritorialisasi Keluarga Pemakai Smartphone Di Kota Surakarta). Diunduh dari https://www.google.com/url?sa=t\&rct=i\&q=\&esrc=s\&source $=$ web\&cd $=2 \& v e d=2$ ahUKEwiE2pyV1ffkAhVX63MBHRI6BzMQFjABegQIARAC\&url=http\%3A\%2F\% 2Feprints.ums.ac.id\%2F62119\%2F1\%2FNASKAH\%2520PUBLIKASI.pdf\&usg= AOvVaw3I IABW oFyUca8slJeXRo pada tanggal 30 September 2019 